\title{
Outcome of uterine rupture and associated factors in Yirgalem general and teaching hospital, southern Ethiopia: a cross- sectional study
}

Achamyelesh Gebretsadik ${ }^{1 *}$, Hailemichael Hagos ${ }^{2}$ and Kebede Tefera ${ }^{1}$

\begin{abstract}
Background: The occurrence of uterine rupture has dropped significantly in high income countries. It continues, however, to be a major public and clinical health problem in low income countries including Ethiopia. Aim of this study was to assess management outcomes of uterine rupture and associated factors in Yirgalem General and Teaching Hospital in South Ethiopia.

Methods: Institution-based cross-sectional study was conducted to examine medical records of women with uterine rupture between January 1, 2012, and Decem"ber 31, 2017. Data were collected based on a checklist. Descriptive statistics and logistic regression analyses were performed.

Results: Incidence of uterine rupture was 345 in 13,500 live births (25.5 in 1000 live births) in the study period. Of these, 331 cases were included. Poor maternal outcome occurred in 224 (67.7\%) women. There were 13 (3.7\%) maternal deaths and 320 (96.7\%) stillbirths. Wound site infection $(131 ; 39.6 \%)$ and anemia $(129 ; 39 \%)$ were the most common post-operative complications. Prolonged duration of labor (more than $24 \mathrm{~h}$ ) (adjusted odds ratio (aOR) 3.6; 95\% Cl 1.7-7.4), women with sepsis on admission (aOR 2.9; 95\% Cl 1.4-6.1), hemoglobin level $<7 \mathrm{~g} / \mathrm{dl}$ prior to surgical intervention (aOR 4.5; 95\% Cl 1.1-17.8), delayed surgical intervention after hospitalization ( $4 \mathrm{~h}$ or more before surgery) (aOR 3.8; 95\% Cl 1.8-8), women who did not receive blood transfusion (aOR 4.0; 95\% Cl 2.1-7.9) and prolonged intraoperative time (aOR 5.5; $95 \% \mathrm{Cl} 2.8-10.8)$ were all factors associated with poor maternal outcome of uterine rupture.

Conclusion: Poor maternal outcome of uterine rupture was high in the study area as compared to other studies. Proper management of anemia, prompt surgical treatment, proper labor progress monitoring, surgical skills, improved infection prevention, maximizing blood transfusion availability and improving the quality of maternal healthcare all play a significant role in reducing uterine rupture and enhancing the chance of good outcomes.
\end{abstract}

Keywords: Uterine rupture, Outcome, Ethiopia

\footnotetext{
*Correspondence: agtsadik@gmail.com

'School of Public Health, College of Medicine and Health Science, Hawassa University, P.O. Box 1466, Hawassa, Ethiopia

Full list of author information is available at the end of the article
}

(c) The Author(s). 2020 Open Access This article is licensed under a Creative Commons Attribution 4.0 International License, which permits use, sharing, adaptation, distribution and reproduction in any medium or format, as long as you give appropriate credit to the original author(s) and the source, provide a link to the Creative Commons licence, and indicate if changes were made. The images or other third party material in this article are included in the article's Creative Commons licence, unless indicated otherwise in a credit line to the material. If material is not included in the article's Creative Commons licence and your intended use is not permitted by statutory regulation or exceeds the permitted use, you will need to obtain permission directly from the copyright holder. To view a copy of this licence, visit http://creativecommons.org/licenses/by/4.0/ The Creative Commons Public Domain Dedication waiver (http://creativecommons.org/publicdomain/zero/1.0/) applies to the data made available in this article, unless otherwise stated in a credit line to the data. 


\section{Background}

Uterine rupture may occur in an intact or scarred gravid uterus from previous caesarean section or other uterine surgeries [1]. It results in significant maternal and perinatal morbidity and mortality [2].

In 2015, worldwide 303,000 women died every year due to complications of pregnancy and childbirth [3]. Uterine rupture accounts for $8 \%$ of all maternal deaths with the majority of cases occurring in low-income countries, bearing over $90 \%$ of the burden of all maternal deaths $[4,5]$. Ethiopia continues to have one of the highest maternal and perinatal mortality in sub-Saharan Africa [6-8].

According to the World Health Organization (WHO), a systematic review of maternal mortality and morbidity revealed the incidence of uterine rupture in high income countries to be $0.92 \%$ [4]. However, in low-income countries, a wider variation of uterine rupture prevalence was observed with $1.9 \%$ in Central Africa, $18 \%$ in Burkina Faso and 28\% in Ethiopia [9, 10].

Risk factors for uterine rupture are: oxytocin induction or augmentation, trial of labour after caesarean birth, poor ANC follow up, prolonged labour, home birth, teenage pregnancy, grand multigravidity, low socioeconomic status, poor infrastructure and poor referral system [11-13].

Uterine rupture can happen in health facilities due to delays in seeking appropriate care at the onset of labour, delays in referral system and delays of intervention due to lack of skilled human resources and negligence of health professionals that ultimately result in poor outcome [12].

The high perinatal and maternal mortality associated with uterine rupture is occurring largely as a result of improper and delayed management [14-19]. Overall, few studies are available nationally in Ethiopia depicting the outcome of uterine rupture. Therefore, aim of this study was to assess outcome of uterine rupture and its associated factors.

\section{Methods}

\section{Study setting and design}

The study was conducted in Yirgalem General and Teaching Hospital (YGTH) in Yirgalem town, Sidama zone, which is located $318 \mathrm{Km}$ south of Addis Ababa, the capital of Ethiopia and $45 \mathrm{~km}$ south of Hawassa, the capital of Southern Nation Nationalities People Region (SNNPR). Catchment area includes 4.2 million people in the Sidama zone and surrounding area.

The hospital has seven departments, including Obstetrics and Gynecology, where laboring mothers are admitted, monitored and managed accordingly. This department comprises of 3 gynecologists, 4 general practitioners, 3 emergency surgical officers and 18 midwives.
Most cases are referred by neighboring district hospitals and health centers. Total number of births during the six-year period between January 1, 2012 and December 31, 2017 was estimated to be 13,500. The hospital has the capacity to perform basic and comprehensive emergency obstetric care, including management of uterine rupture.

A facility-based cross-sectional survey was conducted through records review among women who were diagnosed with a ruptured uterus during the study period and managed at Yirgalem General and Teaching Hospital.

\section{Study population}

All women admitted with uterine rupture were included. Obstetric and operative theatre records were reviewed. A total of 345 patients' cards were identified and all complete medical records with a diagnosis of uterine rupture were assessed. Patients with incomplete medical records (missing data or records; $n=10$ ) or patients whose records were lost $(n=4)$ were excluded from the study. Thus 331 women could be included.

\section{Data collection}

A checklist was developed to collect data which were then pre-tested. This included socio-demographic data, obstetric history and outcome of uterine rupture. Checklists were prepared in English and data were extracted from the patients' medical records, registration books and available operation theatre records by four data collectors and one supervisor. All data collectors and supervisor were selected using their previous experience in data collection, and based on their profession (being either a nurse or midwife). Before data collection, two days of training were provided by the investigators to familiarize the teams with the study objectives and tools.

Quality of the data was assured by a properly designed data collection format and managed by appropriate supervision of data collectors. The checklists were pretested at YGTH from 2011 medical records for those women with uterine rupture management. Correctness of entered data was evaluated by re-reviewing the patients' medical records by the supervisor.

\section{Data analysis}

Data were checked for errors, coded, entered, cleaned, and analyzed by SPSS version 20.0 statistical package. Descriptive statistics (mean \pm standard deviation, frequencies and proportions) were used to summarize socio-demographic characteristics and logistic regression was conducted to assess risk factors of uterine rupture (95\% CI and $P$-value $<0.05$ as level of significance). Variables with a $p$-value $\leq 0.25$ or unadjusted odds ratios which showed a significant association were entered into 
multivariate binary logistic regression. Goodness of fit was assessed by the Hosmer-Lemeshow test when not significant ( $p$-value $>0.05)$ and omnibus test which showed significance $(P$-values $<0.001)$.

\section{Operational definitions \\ Uterine rupture}

Uterine rupture with complete disruption of the uterine wall only.

\section{Outcome of uterine rupture}

Maternal condition post uterine rupture, including survival, complications like wound site infection, anemia, pelvic abscess, pneumonia, urinary tract infection, vesico-vaginal fistula or maternal death [13].

\section{Stillbirth}

Expulsion of a dead fetus weighing at least $1000 \mathrm{~g}$ [5].

\section{Good maternal outcome}

Those women with uterine rupture who are discharged without any complication [20].

\section{Poor maternal outcome}

Women with uterine rupture who died or developed complications [14].

\section{Pelvic abscess}

A collection of infected fluid in the pouch of Douglas, Fallopian tube, ovary, or parametric tissues.

\section{Results}

\section{Socio -demographic characteristics}

From 2012 up to the end of 2017345 cases of ruptured uterus were identified. Out of these, only 331 had complete medical records available for analysis.

Mean age was 31.47 (SD \pm 5.65$)$ years with a range of $18-40$ years. Rural dwellers accounted for 279 (84.3\%) and urban dwellers for 52 (15.7\%). (Table 1).

Parity ranged from 1 to 11 with a mean of 4 (SD \pm 2.75). The big majority 302 (91.3\%) were multiparous and grandmultiparous women with only $29(8.8 \%)$ primiparous women. The majority $(197 ; 59.5 \%)$ did not attend ANC. Gestational age on admission ranged between 37 and 42 weeks in $258(77.9 \%)$ and $73(22.1 \%)$ were $>42$ weeks of gestation. (Table 1 ).

\section{Clinical features and causes}

Most common complaints were abdominal pain (301; $90.9 \%)$, followed by vaginal bleeding $(280 ; 84.6 \%)$ and cessation of uterine contractions $(265 ; 80.1 \%)$. Intrauterine fetal death, easily palpable fetal parts and shock were the most frequent findings on admission, while sepsis
Table 1 Socio-demographic and obstetric profiles of women who were managed for uterine rupture in Yirgalem general and teaching hospital, Sidama Zone, southern Ethiopia, 2012-2018

\begin{tabular}{lll}
\hline Variables $(N=331)$ & Category & Frequency N (\%) \\
\hline Age $($ Years $)$ & $20-24$ & $14(4.2 \%)$ \\
& $25-29$ & $19(5.7 \%)$ \\
& $30-34$ & $81(24.5 \%)$ \\
& $=>35$ & $93(28.1 \%)$ \\
Rlace of residence & $124(37.5 \%)$ \\
Gestational age in weeks & Urban & $279(84.3 \%)$ \\
Parity & $37-42$ & $52(15.7 \%)$ \\
& $>42$ & $258(77.9 \%)$ \\
Primipara & $73(22.1 \%)$ \\
Duration of labor & $2-4$ & $170(51.8 \%)$ \\
& $>=5$ & $132(39.9 \%)$ \\
ANC visits & $<12 \mathrm{~h}$ & $24(7.3 \%)$ \\
& $12-24 \mathrm{~h}$ & $151(45.6 \%)$ \\
Mother came by referral & $>24 \mathrm{~h}$ & $156(47.1 \%)$ \\
Des & $154(46.5 \%)$ \\
before operation in hrs. & No & $177(53.5 \%)$ \\
& $<4 \mathrm{~h}$ & $172(51.9 \%)$ \\
& $>4 \mathrm{~h}$ & $159(48.1 \%)$ \\
& Yes & $134(40.5 \%)$ \\
& & $197(59.5 \%)$ \\
\hline
\end{tabular}

and anemia was already present in almost half of the women. (Table 2).

The most common cause of uterine rupture was cephalo-pelvic disproportion $(167 ; 50.5 \%)$ followed by malpresentation $(140 ; 42.3 \%)$ and previous uterine scar (62; 18.7\%). (Table 2).

Incidence of uterine rupture in YGTH was 25.5/1000 live births. A complete uterine rupture occurred in 285 $(86.1 \%)$ women. The common site of rupture was anterior and lower segment in $266(80.4 \%)$ followed by left lateral rupture in $33(10 \%)$ women. There were 12 (3.6\%) women with bladder rupture. Surgical procedures took one to four hours (mean $=1.94$; SD \pm 0.89 ). About half of the women $(167 ; 50.5 \%)$ did not receive blood transfusion. Subtotal hysterectomy was performed in almost half (164/331; 49.6\%) and total hysterectomy in 115/331 (34.7\%). (Fig. 1).

The most common postoperative complications were wound site infection 131 (39.6\%), anemia (129; 39\%) and pelvic abscess (112; 33.8\%). Only 96 (29\%) women had no complications. (Table 3 ).

Maternal and perinatal outcome

There were 13 (3.7\%) maternal deaths, with eight women dying from multiple organ failure secondary to 
Table 2 Clinical features and Causes of uterine rupture in Yirgalem general and teaching hospital, Sidama Zone, southern Ethiopia, 2012-2018

\begin{tabular}{lll}
\hline Variables $(N=331)$. & Category & Frequency \\
& & N (\%) \\
\hline Clinical features & Abdominal pain & $301(90.9 \%)$ \\
& Vaginal bleeding & $280(84.6 \%)$ \\
& Cessation of uterine contraction & $265(80.1 \%)$ \\
& Absent fetal heartbeat & $320(96.7 \%)$ \\
Physical findings & Easily palpable fetal parts & $292(88.2 \%)$ \\
& Shock & $248(74.9 \%)$ \\
& Sepsis & $149(45 \%)$ \\
& Cephalopelvic Disproportion & $167(50.5 \%)$ \\
& Malpresentation/malposition & $140(42.3 \%)$ \\
Cause of uterine & Previous uterine scar & $62(18.7 \%)$ \\
rupture & Instrumental delivery & $23(6.9 \%)$ \\
& Augmentation and Induction & $23(6.9 \%)$ \\
& Destructive delivery & $5(1.5 \%)$ \\
\hline
\end{tabular}

septic shock and five from cardiorespiratory arrest secondary to hypovolemic shock. All deaths occurred among women who did not attend ANC. Regarding the overall prognosis, $224(67.7 \%)$ had a poor maternal outcome, and all women had a hospital stay of at least eight days. There were 320 (96.7\%) stillbirths, of which 10 (3.3\%) were macerated. (Fig. 2).

\section{Factors associated with poor outcome}

Binary logistic analysis indicated rural residence, women without attending ANC, prolonged labor $(>24 \mathrm{~h})$, delay of surgical intervention ( $>4 \mathrm{~h}$ after hospitalization), prolonged surgical procedures $(>2 \mathrm{~h}$ ), sepsis (septic shock), complete uterine rupture, not receiving blood transfusion, and hemoglobin level $<7 \mathrm{mg} / \mathrm{dl}$ on admission to be significantly associated with poor maternal outcome.

In a multivariate logistic regression analysis, hemoglobin level $<7 \mathrm{mg} / \mathrm{dl}$ on admission (aOR 4.5; 95\% CI 1.1,17.8), delay of surgical intervention $>4 \mathrm{~h}$ after hospitalization (aOR 3.8; 95\% CI 1.8, 8), prolonged labor > $24 \mathrm{~h}$ (aOR 3.6; 95\% CI 1.7, 7.4), maternal sepsis on admission (aOR 2.9; 95\% CI 1.4, 6.1), no blood transfusion (aOR 4; 95\% CI 2.1, 7.9) and intraoperative duration $>2 \mathrm{~h}(\mathrm{aOR} 5.5$; 95\% CI $2.8,10.8)$ were all associated with poor maternal outcome. (Table 4).

\section{Discussion}

Poor maternal and perinatal outcome of uterine rupture was high in Southern Ethiopia (67.7\%) and remains one of the most serious obstetric complications. Most women did not attend ANC. Duration of hospital stay before operation for $\geq 4 \mathrm{~h}$, hemoglobin level $<7 \mathrm{~g} / \mathrm{dl}$ before operation, prolonged labor, sepsis, prolonged duration of the surgical intervention and not available blood transfusion were statistically significant associated factors.

\section{Surgical procedure done for uterine rupture}

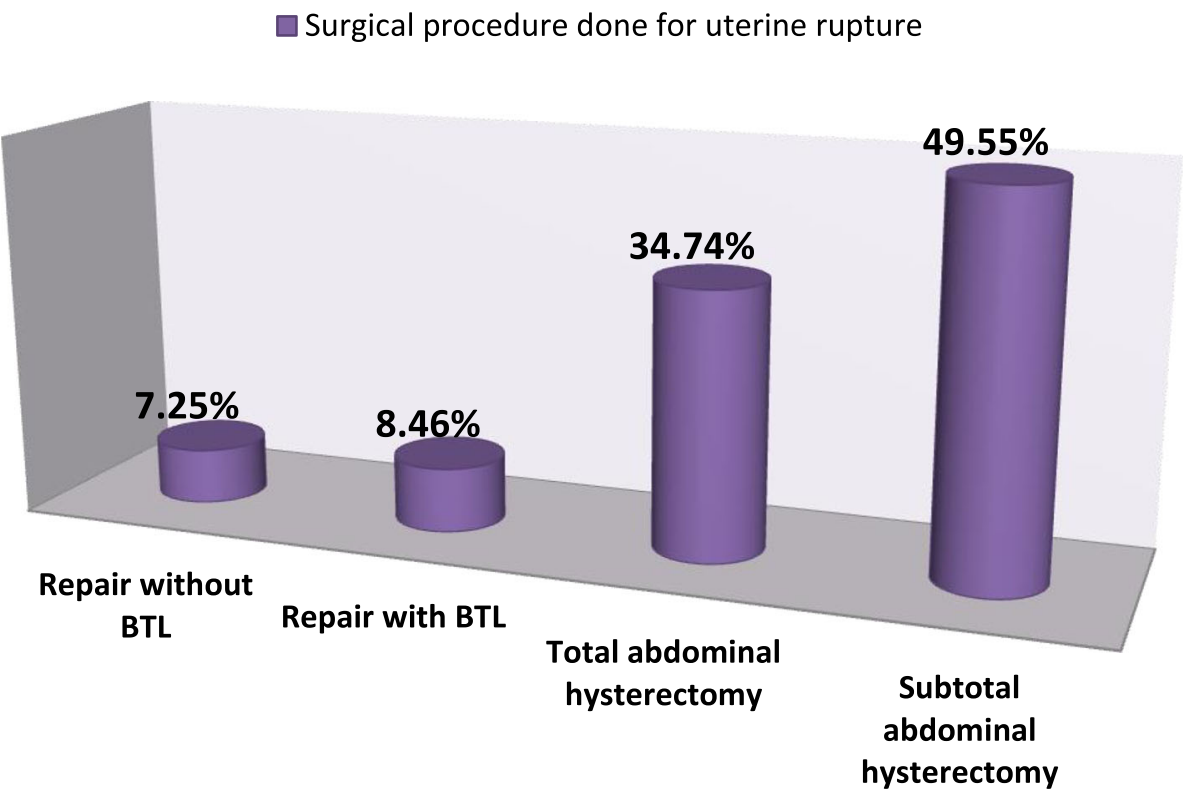

Fig. 1 Surgical procedures for uterine rupture in Yirgalem general and teaching hospital, Sidama Zone, southern Ethiopia, 2018 
Table 3 Post-operative complications

\begin{tabular}{lll}
\hline Variable & Category & Frequency $(N=331)$ \\
\hline Complication & Wound site infection & $131(39.6 \%)$ \\
& Anemia & $129(39 \%)$ \\
& Pelvic abscess & $112(33.8 \%)$ \\
& Pneumonia & $47(14.2 \%)$ \\
& Urinary tract infection & $36(10.9 \%)$ \\
& Vesico-vaginal fistula & $7(2.1 \%)$ \\
& No complication & $96(29 \%)$ \\
\hline
\end{tabular}

Multiple responses possible

The incidence of uterine rupture of 25.5/1000 live births was higher than in studies in Uganda and India $[21,22]$. Overall, $67.7 \%$ of cases resulted in poor maternal outcome. This was much higher than in studies in high income countries (15\%) [19].

This variation could be due to delay of health-seeking behavior, poor quality of health care services, shortage of blood and blood products for transfusion, prolonged operating time due to lack of professional technical skills and severity of uterine rupture.

During this period, case fatality rate was $3.7 \%$ after emergency hysterectomy due to heavy vaginal bleeding or sepsis, which led to hypovolemic or septic shock. Considering lack of blood and delayed treatment, many women developed sepsis and multiorgan failure. These findings are comparable to a study in Debremarkos Hospital [20], but lower than another one in Shashemene Hospital [23].

This study showed that women with hemoglobin levels $<7 \mathrm{~g} / \mathrm{dl}$ prior to surgical intervention was significantly associated with poor maternal outcome. This is partially explained by the fact that anemic women have decreased oxygen carrying capacity with subsequent delayed wound healing and increased risk for infection. This is consistent with studies performed in Suhul General Hospital at Tigrai and Debremarikos [7, 20]. Improving hemoglobin levels during pregnancy is an important part of ANC. A striking feature in our study was a gestational age $>42$ weeks in $22.1 \%$. This is likely a result from late ANC booking and calls for early initiation of ANC in the first trimester.

Prolonged labor/obstructed labor was significantly associated with poor outcomes. Appropriate use of partograph and monitoring progress of labor as well as prompt intervention within $4 \mathrm{~h}$ after admission is necessary to prevent both fetal and maternal morbidity and mortality [24]. These findings are consistent with studies in Suhul General Hospital at Tigrai, Mizantepi Hospital, and Nnamdi Azikiwe University Teaching Hospital Nnewi, Southeast Nigeria [7, 14, 15].

A statistically significant association was also noted with a prolonged surgical procedure of $>2 \mathrm{~h}$ duration. Increased blood loss and postoperative anemia, increased risks of infection, prolonged exposure to anesthesia drugs which predispose to aspiration pneumonia and other drug side effects are determinants of poor maternal outcome. In addition, professionals may lack experience and skills leading to prolonged surgical procedures and complications. This was reported also in a study from the University of Pakistan teaching hospital [17].

Not receiving blood transfusion was statistically associated with poor maternal outcome in uterine rupture. This is likely explained by tremendous vaginal bleeding which is common in uterine rupture. Resuscitation with blood transfusion may prevent development of serious complications. This is consistent with a study from the Medical College of India [18].

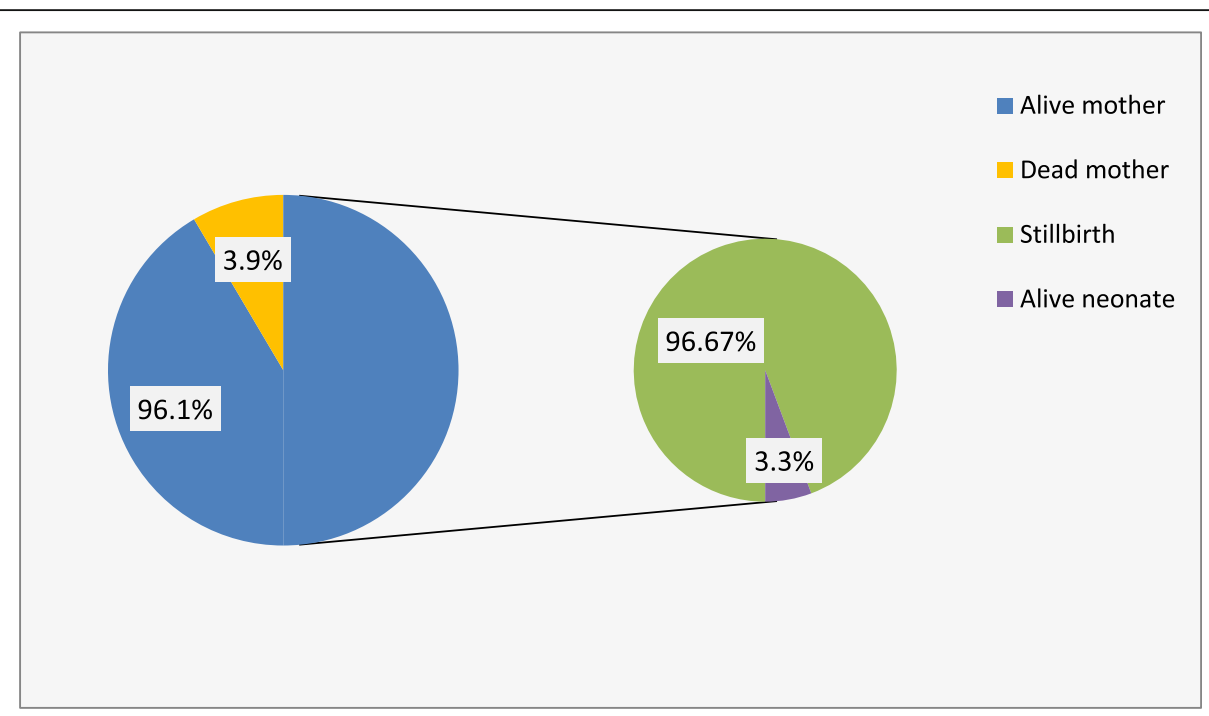

Fig. 2 Maternal and Perinatal outcome of uterine rupture in Yirgalem General \& Teaching Hospital from 2012 to 2018 
Table 4 Factors associated with poor maternal outcome of uterine rupture

\begin{tabular}{|c|c|c|c|c|}
\hline \multirow[t]{2}{*}{ Variables } & \multicolumn{2}{|c|}{$\begin{array}{l}\text { Poor outcome of } \\
\text { uterine rupture }\end{array}$} & \multirow[t]{2}{*}{$\mathrm{cOR}(95 \% \mathrm{Cl})$} & \multirow[t]{2}{*}{$\mathrm{aOR}(95 \% \mathrm{Cl})$} \\
\hline & Yes (\%) & No (\%) & & \\
\hline \multicolumn{5}{|l|}{ Residence } \\
\hline Urban & $22(42.3 \%)$ & $30(57.7 \%)$ & 1 & 1 \\
\hline Rural & $202(72.4 \%)$ & 77 (27.6\%) & $3.57(1.9-6.5)^{*}$ & $2(0.83-4.7)$ \\
\hline \multicolumn{5}{|c|}{ Time from admission to surgery } \\
\hline$<4 h$ & $82(47.7 \%)$ & $90(52.3 \%)$ & 1 & 1 \\
\hline$=>4 \mathrm{~h}$ & $142(89.3 \%)$ & $17(10.7 \%)$ & $9.2(5-16.5)^{*}$ & $3.8(1.8-8)^{*}$ \\
\hline \multicolumn{5}{|c|}{ Type of uterine rupture } \\
\hline Complete & 208 (73\%) & 77 (27\%) & $5(2.6-9.8)^{*}$ & $2.2(0.96-5)$ \\
\hline Incomplete & $16(34.8 \%)$ & $30(65.2 \%)$ & 1 & 1 \\
\hline \multicolumn{5}{|c|}{ Hemoglobin level } \\
\hline$<7 \mathrm{~g} / \mathrm{dl}$ & 57 (93.4\%) & $4(6.6 \%)$ & $8.7(3.1-24.9)^{*}$ & $4.5(1.1-17.8)^{*}$ \\
\hline$=>7 \mathrm{~g} / \mathrm{dl}$ & $167(61.9 \%)$ & $103(38.1 \%)$ & 1 & 1 \\
\hline \multicolumn{5}{|l|}{ ANC } \\
\hline Yes & $63(47 \%)$ & 71 (53\%) & 1 & 1 \\
\hline No & $161(81.7 \%)$ & $36(18.3)$ & $5(3-8.3) *$ & $1.6(.78-3.3)$ \\
\hline
\end{tabular}

Sepsis on admission

$\begin{array}{lllll}\text { Yes } & 130(87.2 \%) & 19(12.8 \%) & 6.4(3.6-11.2)^{*} & 2.9(1.4-6.1) * \\ \text { No } & 94(51.6 \%) & 88(48.4 \%) & 1 & 1\end{array}$

Duration of lab or in hr.

$\begin{array}{lllll}>24 \mathrm{~h} . & 131(84 \%) & 25(16 \%) & 4.6(2.7-7.7) * & 3.56(1.7-7.4) * \\ <24 \mathrm{~h} . & 93(53.1 \%) & 82(46.9 \%) & 1 & 1 \\ \text { Blood transfused } & & & \\ \text { Yes } & 88(53.7 \%) & 76(46.3 \%) & 1 & 1 \\ \text { No } & 136(81.4 \%) & 31(18.6 \%) & 3.8(2.3-6.2)^{*} & 4(2.1-7.9) *\end{array}$

Surgery length

\begin{tabular}{lllll}
$=>2 \mathrm{~h}$ & $173(84.8 \%)$ & $31(15.2 \%)$ & $8.3(4.9-14) *$ & $5.5(2.8-10.8)^{*}$ \\
$<2 \mathrm{~h}$ & $51(40.2 \%)$ & $76(59.8 \%)$ & 1 & 1 \\
\hline
\end{tabular}

Note: ${ }^{*} p<0.05$

A woman with sepsis on admission was more likely to develop complications and multiple end organ failure resulting from infection-related hypotension and unbalanced inflammatory response $[1,13]$. A similar finding was reported in Tanzania [25]. Women with sepsis were at high risk of developing multiorgan failure, due to aggressive immune-mediated organ injury leading to severe septic shock and death $[1,13]$.

\section{Limitations of the study}

All data were collected from secondary sources (medical records) and not supported by direct observation and interviewing of the women. Another challenge was poor documentation and inconsistencies of medical records. Results of our facility-based study may not be generalizable for the community at large.

\section{Conclusion}

Poor maternal outcome among women with uterine rupture managed in Yirgalem General and Teaching Hospital was high compared to other studies. Delayed surgical intervention, hemoglobin $<7 \mathrm{~g} / \mathrm{dl}$ and sepsis before surgical intervention, prolonged duration of labor, prolonged duration of surgery and lack of blood transfusion were all factors associated with poor outcome. Therefore, the government and other responsible stakeholders should focus attention on proper and immediate identification of risk factors and initiation of timely management. Capacity building through training of healthcare professionals, assessing barriers to blood transfusion, and improving access to ANC and standard care during pregnancy, including early calculation of gestational age, and childbirth are crucial to prevent and better manage uterine rupture. Proper labor follow-up and infection prevention and control are also important for better outcome. Maximizing the quality of maternal health care is crucial for reducing maternal and perinatal morbidity and mortality.

\section{Abbreviations}

aOR: Adjusted Odds Ratio; ANC: Antenatal Care; cOR: Crude Odds Ratio; GA: Gestational age; SNNPR: Southern Nation Nationalities People Region; YGTH: Yirgalem General and Teaching Hospital

\section{Acknowledgments}

The authors would like to thank Hawassa University, College of Medicine and Health Sciences for financial support to carry out this research. We are thankful to Yirgalem General and Teaching Hospital, Obstetrics and Gynecology department, office of the Medical Director and Operation staff. Lastly, the authors would like to thank the data collectors and medical records workers, without whom this study could not have been conducted.

\section{Authors' contributions}

$A G, H H$ and $K T$ were involved in the conception and design of the study, data collection, data supervision, data processing, cleaning, analysis and interpretation of the results, and developing the manuscript. Each gave final approval of the version to be published and agree to be accountable for all aspects of the work.

Funding

No funding was received for this research.

\section{Availability of data and materials}

The datasets generated and/or analyzed during the current study available from the corresponding author on reasonable request.

\section{Ethics approval and consent to participate}

Approval of this study was given by the research and the ethics committee of the School of Public Health and the Institutional Review Board of the College of Medical and Health Sciences at Hawassa University. Permission to undertake this study was also obtained from Yirgalem General hospital administrative director then an official letter was sent to the medical record department from the chief clinical service officer of the hospital. Since all data was secondary data and obtained directly from medical records with no direct contact with patients, consent, waiver was requested and granted from the IRB. To insure privacy and confidentiality of sensitive information, names were replaced with codes of each participant.

Consent for publication

Not applicable. 


\section{Competing interests}

The authors declare that they have no competing interests.

\section{Author details}

${ }^{1}$ School of Public Health, College of Medicine and Health Science, Hawassa University, P.O. Box 1466, Hawassa, Ethiopia. ${ }^{2}$ School of Medicine, Department of Obstetrics and Gynecology, Hawassa University, Hawassa, Ethiopia.

Received: 2 January 2020 Accepted: 14 April 2020

Published online: 28 April 2020

\section{References}

1. Nicolás I. Uterine rupture and pregnancy current vision: scientific evidence and consensus with the patient. Reproductive Immunol. 2016;3(19):1-4.

2. den Akker V, Mwagomba B, Irlam J, Van Roosmalen J. Using audit to reduce the incidence of uterine rupture in a Malawian District hospital. Int J Gynecol Obstet. 2009;107:289-94.

3. World Health Organization. Trends in Maternal Mortality: 1990 to 2015 Estimates by WHO, UNICEF, UNFPA. In: World Bank Group and the United Nations Population Division. Geneva: World health Organization; 2015

4. Gülmezoglu A, Say L, Betrán A, Villar J, Piaggio G. World Health Organization systemic review of maternal mortality and morbidity methodological issues and challenges. BMC Med Res Methodol. 2004;4(16):5-8.

5. Mengistie $H$, Amenu D, Mengistie B. Maternal and perinatal outcomes of uterine rupture patient are among Mothers who delivered at Mizan Aman General Hospital, A five year retrospective hospital based study. MOJ Womens Health. 2016;2(1):13-23.

6. Aliyu $\mathrm{S}$, Yizengaw T. Prevalence and associated factors of uterine rupture during labor among women who delivered in Debre Markos hospital north West Ethiopia. Intern Med. 2016;6(222):3-6.

7. Marie T, Mulat A, Eshetie T. Associated factors and outcomes of uterine rupture at Suhul general hospital, shire town, north West Tigray. Ethiopia Int J Gynecol Obstet. 2017;2017:4-7.

8. Centeral statistical agency Ethiopia. Maternal and perinatal morbidity and mortality. Ethiopia Demographic and Health Survey; 2016.

9. Hofmeyr GJ, Say L, Gulmezoglu AM. WHO systematic review of maternal mortality and morbidity: the prevalence of uterine rupture. BJOG. 2005; 112(9):1221-8.

10. Berhan $Y$, Berhan A. Causes of maternal mortality in Ethiopia: a significant decline in abortion related death. Ethiop J Health Sci. 2014;24:15-28.

11. Vladimir R, Aruna M, Sambit M, Tahir M. A case series of uterine rupture: lessons to be learned for future clinical practice. J Obstet Gynaecol India. 2013;62(6):665-73.

12. Yemane $Y$, Giza W. Assessement of the associated factors, management and complications of uterine rupture at Mizan Tepi University teaching hospital. Mizan Aman Town Health Sci J. 2017;11(3):1-9.

13. Chibber R, El-Saleh E, Al Fadhli R, Al Jassar W, Al Harmi J. Uterine rupture and subsequent pregnancy outcome - how safe is it? A 25-year study. J Matern Fetal Neonatal Med. 2010;23(5):421-4.

14. Dadi T, Yarinabab T. Estimates of uterine rupture bad outcomes using propensity score and determinants of uterine rupture in Mizan-Tepi University teaching hospital. J Pregnancy. 2017;25(6):1-10.

15. Mbamara S, Obiechina N, Eleje G. An analysis of uterine rupture at the Nnamdi Azikiwe University teaching hospital Nnewi, Southeast Nigeria. Niger J Clin Pract. 2012;15(4):448-52.

16. Gebre $S$, Negassi A. Risk factors for uterine rupture in Suhul general hospital case control study. Electronic J Bio. 2017;13(3):198-202.

17. Aziz N, Yousfani S. Analysis of uterine rupture at university teaching hospital Pakistan. Pak J Med Sci. 2015;31(4):920-92.

18. Sunanda N, Priya R. A two-year analysis of uterine rupture in pregnancy. Int J Reprod Contracept Obstet Gynecol. 2016;5:3983-6.

19. Vandenberghe $\mathrm{G}$, Bloemenkamp K, Berlage $\mathrm{S}$, et al. The international network of obstetric survey systems study of uterine rupture: a descriptive multi-country population-based study. BJOG. 2019;126:370-81.

20. Astatikie $G$, Kebede M, Limenh M. Maternal and fetal outcomes of uterine rupture and associated with maternal death secondary to uterine rupture. BMC Pregnancy Child Birth. 2017;17(117):42-9.

21. Mukasa PK, Kabakyenga J, Senkungu JK, Ngonzi J, Kyalimpa M, van Roosmalen J. Uterine rupture in a teaching hospital in Mbarara, western Uganda, and unmatched case- control study. Reprod Health. 2013;29(10):29.
22. Sinha M, Gupta R, Gupta P, et al. Uterine rupture: a seven year review at a tertiary Care Hospital in new Delhi. India Indian J Community Med. 2016; 41(1):45-9.

23. Chamiso B. Rupture of the pregnant uterus in Shashemene general hospital. Ethiopian Med J. 2010;33(4):251-7.

24. Mathai M. The partograph for the prevention of obstructed labor. Clin Obstet Gynecol. 2009;52(2):256-69.

25. Kidanto H, Mwampagatwa I, van Roosmalen J. Uterine rupture: a retrospective analysis of causes, complications and management outcomes at Muhimbili National Hospital in Dar Es Salaam, Tanzania. Tanzan J Health Res. 2012;14(3):1-9.

\section{Publisher's Note}

Springer Nature remains neutral with regard to jurisdictional claims in published maps and institutional affiliations.
Ready to submit your research? Choose BMC and benefit from:

- fast, convenient online submission

- thorough peer review by experienced researchers in your field

- rapid publication on acceptance

- support for research data, including large and complex data types

- gold Open Access which fosters wider collaboration and increased citations

- maximum visibility for your research: over $100 \mathrm{M}$ website views per year

At BMC, research is always in progress.

Learn more biomedcentral.com/submissions 